\title{
LA METAFÍSICA EN EL TOMISMO TRASCENDENTAL DE BERNARD LONERGAN Y EMERICH CORETH \\ Carlos Gutiérrez Lozano*
}

RESUMEN: El artículo expone y compara las doctrinas metafísicas de dos filósofos pertenecientes a la corriente denominada tomismo trascendental: Bernard Lonergan y Emerich Coreth. Se resalta el concepto, el método y el punto de partida de la metafísica en los dos autores. Ambos intentan superar a Kant en la aplicación del método trascendental e intentan mostrar el ser como la condición última de posibilidad de toda realización cognoscitiva humana.

\section{yose \\ BERNARD LONERGAN AND EMERICH CORETH'S METAPHYSICS \\ IN TRANSCENDENTAL THOMISM}

ABSTRACT: In this article, we present and compare the metaphysical doctrines of two philosophers of the school of thought known as transcendental thomism: Bernard Lonergan and Emerich Coreth. We will highlight their ideas regarding metaphysics, methods, and points of view. Both philosophers attempt to go beyond Kant in the use of the transcendental method and attempt to portray the being as the ultimate condition of possibility in all human cognitive achievement.

PALABRAS CLAVE: Coreth, Lonergan, metafísica, método trascendental.

KEY WORDS: Coreth, Lonergan, metaphysics, transcendental method.

RECEPCIÓN: 2 de enero de 2014.

APROBACIÓN: 6 de enero de 2015.

* Departamento de Estudios Generales ITAM. 
CITAM Derechos Reservados.

La reproducción total o parcial de este artículo se podrá hacer si el ITAM otorga la autorización previamente por escrito. 


\section{LA METAFÍSICA \\ EN EL TOMISMO \\ TRASCENDENTAL \\ DE BERNARD \\ LONERGAN Y \\ EMERICH CORETH}

\section{Introducción}

\section{La encíclica Aeterni Patris, del Papa}

León XIII (1810-1903), de 1879 marcó el inicio de una extraordinaria renovación de la filosofía escolástica, sobre todo aquella centrada en Tomás de Aquino. ${ }^{1}$ La renovación se realizó en dos frentes bien definidos: por un lado, la investigación histórica sobre la auténtica filosofía del Aquinate y, por la otra, los intentos de diálogo con diversos hitos de la filosofía moderna: Descartes, Kant, Hegel, Husserl, Heidegger. Destacó particularmente la corriente que intentó unir los contenidos de la filosofía tomasiana con el método trascendental kantiano. Por ello recibió el nombre de tomismo trascendental. En este artículo exponemos y comparamos el intento metafísico del sacerdote jesuita Bernard

${ }^{1}$ El Papa exhorta en su encíclica a todos los obispos del mundo con las siguientes palabras: "Nos, pues [...], a vosotros todos, venerables hermanos, con grave empeño exhortamos a que, para defensa y gloria de la fe católica, bien de la sociedad e incremento de todas las ciencias, renovéis y propaguéis latísimamente la áurea sabiduría de Santo Tomás. [...]. Por lo demás procuren los maestros elegidos inteligentemente por vosotros, insinuar en los ánimos de sus discípulos la doctrina de Tomás de Aquino, y pongan en evidencia su solidez y excelencia sobre todas las demás. Las Academias fundadas por vosotros, o las que habéis de fundar, ilustren y defiendan la misma doctrina y la usen para la refutación de los errores que circulan. Mas para que no se beba la supuesta doctrina por la verdadera, ni la corrompida por la sincera, cuidad de que la sabiduría de Tomás se tome de las mismas fuentes o al menos de aquellos ríos que, según cierta y conocida opinión de hombres sabios, han salido de la misma fuente y todavía corren íntegros y puros" 
Lonergan (1904-1984), contenido en su obra de 1957 Insight, y la doctrina metafísica del también sacerdote jesuita Emerich Coreth (19192006) publicada en 1961 bajo el título de Metafísica. Ambos recibieron la influencia fundamental del también sacerdote jesuita Joseph Maréchal (1878-1944), ${ }^{2}$ quien en su obra El punto de partida de la metafísica puso como lema: superar a Kant por medio de Kant.

\section{Concepto de metafísica}

\section{Concepto lonerganiano de metafísica}

En su monumental obra Insight Lonergan se propone responder a tres preguntas fundamentales: ¿Qué pasa cuando conocemos? ¿Por qué tal actividad es conocer? ¿Qué es conocido cuando pasa esto ${ }^{3}$ La primera pregunta apunta a la teoría del conocimiento, la segunda a la epistemología y la tercera a la metafísica. A este respecto, Giovanni Sala comenta que tanto las preguntas como las respectivas ciencias que responden a ellas, están íntimamente relacionadas y constituyen una única y total ciencia del conocimiento trascendente. ${ }^{4}$

En la primera parte de Insight, titulada "El acto de intelección en cuanto actividad", Lonergan responde a las dos primeras preguntas, analizando cómo ocurre el conocimiento en las matemáticas, en las ciencias y en el sentido común. En la segunda parte, "El acto de intelección en cuanto conocimiento", responde a la tercera pregunta, ahí aparece su concepción de la metafísica; esta brota de la teoría del

${ }^{2}$ Maréchal es especialmente conocido por la confrontación que realiza entre tomismo y filosofía crítica de Kant a partir de Santo Tomás. Trata de superar el agnosticismo kantiano por dos vías convergentes: la primera, indirecta y constructiva, contesta histórica y teóricamente la legitimidad de las exigencias metodológicas del criticismo; la segunda, directa y polémica, acepta las premisas kantianas y demuestra que, profundizando en ellas, fuerzan a la afirmación incluso teórica del absoluto nouménico «http://www.mcnbiografias.com/app-bio/do/show?key= marechal-joseph», consultado el 2 de diciembre de 2014.

${ }^{3}$ Bernard Lonergan, Insight. Estudio sobre la comprensión humana, 1999, México/Salamanca, UIA/Sígueme, tr. Francisco Quijano, p. 25 (en adelante, Insight).

${ }^{4} \mathrm{Cfr}$. Giovanni Sala, "La métaphysique comme structure heuristique selon Bernard Lonergan", en $\mathrm{ArPh}$ 33, 1970, p. 49. 
conocimiento presente en el sujeto y de la epistemología, es decir, la ciencia que pone en relación la teoría del conocimiento con la realidad, y debe ser coherente con ambas.

Lonergan muestra que las matemáticas, las ciencias y el sentido común son productos concretos de la capacidad cognoscitiva del hombre. Si estos conocimientos parciales tienen un mismo fundamento, él se pregunta si puede haber una ciencia que sostenga, penetre, transforme y unifique todos los campos del conocimiento humano, ${ }^{5}$ la metafísica será la respuesta a esta pregunta. Ahora bien, Lonergan está de acuerdo con la tradición aristotélico-tomista al señalar que el ser en cuanto ser es el objeto formal de la metafísica. Pero, para él, el ser solo llega a ser objeto de la metafísica cuando es conocido y afirmado por el hombre.

Pues definimos el ser por su inteligibilidad; sostenemos que el ser es precisamente lo que es conocido cuando comprendemos correctamente; negamos que el ser sea algo fuera o más allá o diferente de lo inteligible, pues la definición que proponemos implica que el ser es conocido completamente cuando ya no hay más preguntas por responder. ${ }^{6}$

Según esto, el concepto de ser no admite una definición directa o de primer orden, sino solo una definición que determine cómo se debe llegar a ella o de segundo orden; en definitiva, para Lonergan la definición de ser solo puede darse de una manera operativa, como la meta del conocimiento humano. ${ }^{7}$

Lonergan coincide, además, con la tradición, al matizar que el ser propio y proporcionado a la capacidad humana es la quididad abstracta de las cosas materiales. A este respecto escribe:

En su amplitud cabal, el ser es todo aquello que ha de ser conocido mediante la aprehensión inteligente y la afirmación razonable. Pero el ser proporcionado al conocimiento humano no solo ha de ser compren-

${ }^{5}$ Cfr. Insight, p. 464.

${ }^{6}$ Ibid., p. 583.

${ }^{7}$ Cfr. W. S. Arndt, "Bernard J. F. Lonergan (1904-1984)", en Emerich Coreth et al. (comps.), Filosofia cristiana en el pensamiento católico de los siglos XIX y XX, 1997, Madrid, tomo 2, Encuentro, pp. 695-696. 
dido y afirmado, sino también ha de ser experimentado. Así pues, el ser proporcionado puede definirse como todo aquello que ha de ser conocido mediante la experiencia humana, la aprehensión inteligente y la afirmación razonable. ${ }^{8}$

Ahora bien, si la metafísica es la ciencia del ser, ella será posible solo si es capaz de determinar heurísticamente, es decir, anticipando, las características generales del universo del ser proporcionado. Estas llegarán a ser conocidas a través de los actos cognoscitivos del hombre, aunque, de hecho, el conocimiento concreto no se haya realizado; de aquí surge la peculiar definición lonerganiana de metafísica: "la metafísica explícita es la concepción, la afirmación y la implantación de la estructura heurística integral del ser proporcionado".

Lonergan explica detalladamente cada uno de los elementos de esta definición en estos términos:

Una noción heurística, por tanto, es la noción de un contenido desconocido y queda determinada al anticipar el tipo de acto mediante el cual aquello desconocido llegaría a ser conocido. Una estructura heurística es un conjunto ordenado de nociones heurísticas. En fin, una estructura heurística integral es el conjunto ordenado de todas las nociones heurísticas". ${ }^{10}$

En esta noción aparecen claramente los elementos que Lonergan toma de las ciencias y del sentido común, mediante el análisis fenomenológico.

En esta detallada explicación, se ve claramente que Lonergan se vale de categorías epistemológicas para explicar el contenido de la ciencia metafísica. ${ }^{11}$ En efecto, para él, el conocimiento está orientado esencialmente hacia el ser y el ser está referido esencialmente al conocimiento. Aquí se vislumbra ya su famosa teoría acerca del isomorfismo entre el conocer y lo conocido. A este respecto escribe: "ahora

${ }^{8}$ Insight, p. 466.

${ }^{9}$ Loc. cit.

${ }^{10}$ Ibid., pp. 466-7.

${ }^{11}$ Lonergan afirma que esta perspectiva empleada por él se justifica en la doctrina de Tomás de Aquino. Cfr. "Insight: Preface to Discussion", en F. E. Crowe (ed.), Collection. Papers by Bernard Lonergan, 1968, Nueva York, Herder and Herder, pp. 152-63. 
bien, conocer es conocer el ser. Así, la estructura heurística integral del ser proporcionado, en cuanto determinada por las ciencias y el sentido común, es el conocimiento de la estructura organizadora del ser proporcionado". ${ }^{12}$

Según esto, la estructura del conocimiento da a conocer la estructura de lo conocido; de aquí que Lonergan conciba el ser proporcionado como compuesto de elementos metafísicos.

Lonergan ha indicado que el ser es aquello que se alcanza por el conocimiento humano. Pero el conocimiento es un conjunto de operaciones, a saber: experiencia, entendimiento y reflexión. Ahora bien, con base en el principio del isomorfismo entre el conocer y lo conocido, afirma que en el ser proporcionado se dan elementos metafísicos que son correlatos objetivos de cada acto de conocimiento. El elemento metafísico que es conocido por la experiencia es la potencia; lo que es conocido por la captación inteligente es la forma, y lo que es conocido por el juicio reflexivo es el acto. Por lo tanto, así como el conocimiento humano es uno solo, con los niveles de experiencia, entendimiento y reflexión, así también el ser es uno solo, formado por los elementos metafísicos de potencia, forma y acto; estos dan a conocer la estructura metafísica del ser proporcionado.

La clasificación de los elementos metafísicos efectuada por Lonergan posibilita, por un lado, la unificación de todos los campos del saber humano, función primordial de la metafísica, y responde, por el otro, a la estructura inmanente del universo.

Según lo anterior, la metafísica garantiza que todo lo que se conoce de hecho y lo que queda aún por conocer se da y se dará en las categorías de potencia, forma o acto, según intervengan en el conocimiento la experiencia, el entendimiento o la reflexión. Pero, ¿esto significa que potencia, forma y acto son meras categorías mentales para conocer el ser, a la manera de las categorías a priori del entendimiento de Kant?; los elementos metafísicos ¿solo sirven para unificar los conocimientos o son verdaderamente elementos ontológicos de las cosas individuales y existentes? Para Lonergan este problema no es más que un seudo-

${ }^{12}$ Insight, p. 471. 
problema, porque en cada elemento metafísico se da la intrínseca inteligibilidad del ser. Así, la potencia es inteligible potencialmente, la forma es inteligible formalmente y el acto es inteligible actualmente. Tal inteligibilidad intrínseca es afirmada por el hecho de que el conocimiento es conocimiento del ser.

El objeto proporcionado del conocimiento humano no solo es intrínsecamente inteligible, sino también es necesariamente un compuesto de tres tipos distintos de inteligibilidad. De lo cual se sigue que la potencia, la forma y el acto no establecen simplemente la estructura en la cual el ser es conocido, sino también la estructura inmanente en la realidad misma del ser. ${ }^{13}$

Por lo tanto, como el conocimiento es uno, con los niveles de experiencia, entendimiento y reflexión, así también el ser proporcionado es uno, en sus elementos metafísicos de potencia, forma y acto; la unión entre ambos es la inteligibilidad intrínseca del ser, que es también potencial, formal o actual.

Lonergan se sirve de la deducción para afirmar la posibilidad de la que él llama metafísica explícita. La deducción tendrá como premisa mayor el isomorfismo entre el conocer y lo conocido; la premisa menor primaria estará determinada por las afirmaciones concretas que actualizan la estructura del conocimiento; y la premisa menor secundaria será la reorientación de las ciencias y del sentido común, con base en la estructura del conocimiento entendida y afirmada por el sujeto que conoce. Si el principio de isomorfismo es captado por el sujeto, entonces la metafísica latente deviene metafísica explícita. ${ }^{14}$

Esta deducción permite ver claramente la estrecha relación que hay entre metafísica y ciencias particulares. Por un lado, la metafísica es la ciencia que fundamenta, penetra y unifica todos los departamentos del saber; por otro lado, las ciencias particulares constituyen el material que será unificado por la metafísica.

De lo dicho se desprende que la metafísica solo será explícita si se realiza de acuerdo con el método que sigue el proceso del conocimiento,

${ }^{13}$ Ibid., p. 585.

${ }^{14}$ Cfr. ibid., p. 476. 
ya operante en todo hombre. Esto quiere decir que la metafísica explícita, es decir, el conocimiento de la realidad puesto en conceptos y sistematizado, solo es posible si antes, en términos de Lonergan, es latente, esto es, si está ya presente y operante en el conocimiento humano. El paso de la metafísica latente, como condición de posibilidad, a la metafísica explícita remite a la cuestión del método.

\section{Concepto corethiano de metafísica}

Coreth heredó de sus profesores J. de Vries (1898-1989) y J. B. Lotz (1903-1992) un profundo conocimiento de la doctrina auténticamente tomasiana sobre el ser y la necesidad de dialogar, desde esa base sólida, con la filosofía moderna: Kant, Hegel, Husserl y Heidegger, principalmente. ${ }^{15}$

Coreth asumió seriamente esta tarea y la cumplió de modo original en su obra Metafísica. Una fundamentación metódico-sistemática. ${ }^{16}$ En esta obra expone nuevamente los contenidos de la ontología tradicional, repensándolos y reelaborándolos desde el horizonte de la filosofía moderna; este intento constituye un paso muy significativo dentro del desarrollo histórico del planteamiento metafísico, dadas las características típicas del filosofar moderno, como son la cuestión acerca del método preciso de la metafísica y la vuelta al sujeto. Para Coreth, el esfuerzo por hacer una metafísica que se precie de ser verdaderamente científica en la actualidad no deberá pasar por alto la autofundamentación de la misma a partir de la actual actividad consciente del hombre. ${ }^{17}$ Esta actividad tiene condiciones de posibilidad que la hacen realizable, y es necesario sacarlas a la luz para ponerlas en conceptos: "desde que

15 “Tanto Maréchal como Heidegger quieren hacer visible y fundamentar aquella originaria apertura al ser, esencial al ser humano. Ambos retoman a Kant y aprovechan sus insinuaciones para el despliegue de sus respectivos pensamientos propios". Hildegard Anegg, Gelebte Metaphysik"-Metaphysik fur das Leben. Ein Beitrag zum Verständnis Transzendental Metaphysischen Denkens und Argumentierens, 2014, Innsbruck, tesis doctoral, p. 156.

${ }^{16}$ Emerich Coreth, Metafisica. Una fundamentación metódico-sistemática, 1964, Barcelona, Ariel, tr. Ramón de Areitio (en adelante Metafisica).

${ }^{17}$ Coreth habla de la autorrealización quidditativamente humana. Cfr. Metafísica, p. 70. 
la real y dinámica actividad del sujeto precede a todos los contenidos objetivos de conocimiento y los media como contenidos de conocimiento, debemos empezar nuestra investigación a partir de esta actividad". ${ }^{18}$

Utilizando los elementos mencionados, Coreth construye su metafísica, que él caracteriza como crítica, metódica y sistemática. Pero, ¿qué entiende Coreth por metafísica? ¿Cuáles son las características de la ciencia que pretende fundamentar? Según apunta en las primeras páginas de su obra, es preciso tener un preconcepto de metafísica que, aunque anterior a la posibilidad y realización de la misma, sirva de punto de partida.

Coreth coincide con la tradición aristotélico-tomista al pensar en la metafísica como la ciencia del ser en cuanto ser; sin embargo, en su intento de dialogar con la filosofía moderna, afirma que "metafísica es la ciencia que trata de descubrir y poner de manifiesto metódicamente el conocimiento originario acerca del ser, que precede, fundamentándolo, a todo conocimiento particular acerca del ente". ${ }^{19}$

La metafísica se caracterizará por un conocimiento originario, no conceptual, del ser en su totalidad; este está en la base de cualquier conocimiento particular, como el horizonte dentro del cual se realiza. De este conocimiento previo sobre el ser en su totalidad brotan las dos características principales que Coreth atribuye a la metafísica: ciencia fundamental y ciencia general. ${ }^{20}$

La metafísica es la ciencia filosófica fundamental (Grundwissenschaft) porque, al poner de manifiesto nuestro conocimiento originario acerca del ser y de los principios que de él derivan, en orden a conocer el ente a partir de su fundamento, también saca a la luz los principios de todas las demás disciplinas filosóficas; estas, en efecto, no pueden tener otro fundamento que el ser. La metafísica trata de todo ente en general, pero no en cuanto totalidad numérica, sino que trata de lo más fundamental del ente, a saber, el ser del ente. ${ }^{21}$ La metafísica, por ser la

${ }^{18}$ Emerich Coreth, "The Problem and Method of Metaphysics”, IPQ 3, 1963, p. 414.

${ }^{19}$ Metafisica, p. 7.

${ }^{20}$ Cfr. ibid., pp. 9, 18, 25, 42; idem, "The Problem and Method of Metaphysics", $I P Q 3$, 1963 , p. 416.

${ }^{21}$ Cfr. Metafisica, p. 42. 
ciencia fundamental, es simultáneamente la ciencia general o universal (Gesamtwissenschaft) porque, al abarcar la totalidad de lo real, de lo inteligible, trasciende infinitamente el ámbito de las ciencias particulares y todos los conocimientos empíricos de cada una de ellas. La metafísica como ciencia del ser no investiga sobre el dato meramente empírico, sino que se remonta hasta el fundamento último de la unidad de todos los conocimientos empíricos, el ser del ente. ${ }^{22}$

Pero, ¿es posible fundamentar críticamente una ciencia de tales magnitudes y pretensiones? ¿El ser humano realmente es capaz de tener tal conocimiento originario del ser, siendo que su actividad intelectual está irremediablemente ligada al conocimiento de los sentidos, de las cosas materiales?

Coreth afirma que la metafísica es posible, debido a que el conocimiento previo y fundamental del ser es condición de posibilidad de toda realización particular; pero es un conocimiento atemático e inmediato, que se con-realiza en la actividad intelectual concreta del hombre. Por lo tanto, el conocimiento originario acerca del ser debe ser mediado, de manera que pueda ser conocido reflejamente y pueda ser colocado en conceptos. Tal mediación de lo inmediato apunta insoslayablemente a dos cuestiones esenciales: al método adecuado para realizar la mediación y al punto de partida capaz de propiciar la mediación a partir de sí mismo. Únicamente así la metafísica, como ciencia del ente en cuanto ente, y por ello ciencia fundamental y general, podrá ser realizada crítica, metódica y sistemáticamente.

\section{Semejanzas}

Es sumamente importante tener presentes las críticas y los comentarios que ambos pensadores se hicieron sobre sus respectivas obras principales; estos datos ofrecen la oportunidad de comparar a Lonergan y a Coreth a partir de sí mismos y no solo a través de sus intérpretes y comentadores. $^{23}$

${ }^{22}$ Loc. cit.

${ }^{23}$ Cfr. Bernard Lonergan, “Metaphysics as Horizon”, en F. E. Crowe, Collection, pp. 202-220, la crítica a la metafísica de Coreth; y en Emerich Coreth, "Immediacy and Mediation of 
Como primera y fundamental semejanza, hay que señalar el imponente esfuerzo que llevan a cabo tanto Lonergan como Coreth por elaborar una metafísica sistemática que, abarcando la totalidad de lo real, permitiera igualmente la integración de los conocimientos aportados por las ciencias particulares. El mérito de este esfuerzo estriba en que fue realizado dentro de un ambiente filosófico predominantemente antimetafísico. Otra semejanza se desprende de las características que conceden a la ciencia metafísica. Ambos buscaron, como los antiguos pensadores griegos, el fundamento de todas las cosas; ambos pusieron de manifiesto la insuficiencia radical que caracteriza a las ciencias empíricas y señalaron la necesidad de remontarse al principio fundamentante de todo el saber humano, que es condición de posibilidad del despliegue de las ciencias particulares: el ser. De hecho, los dos coinciden también en atribuir a la metafísica la función de unificar y sostener todos los departamentos particulares del conocimiento humano. Una tercera semejanza estriba en que ambos pensadores asimilaron convenientemente la herencia de la filosofía moderna, en particular la vuelta al sujeto; en efecto, tanto uno como otro parten del sujeto concreto en su realización o autorrealización, con el fin de elaborar la metafísica: "la persona concreta como 'investigador encarnado', debe formar el punto de partida para la reflexión filosófica". ${ }^{24}$ En Lonergan y en Coreth es el hombre real el que, desde el horizonte concreto de su mundo y de su experiencia, se pregunta por el ser.

\section{Diferencias}

Lonergan expresó claramente sus diferencias respecto a Coreth:

Desde el punto de vista de la metodología fundamental, la metafísica no es la primera ciencia. No es la Grund-und Gesamtwissenschaft. Aunque tengo el honor de que se haya asociado mi nombre al del padre

Being”, en P. McShane (ed.), Language, Truth and Meaning. Papers from the International Lonergan Congress 1970, 1970, University of Notre Dame Press, pp. 33-48, la crítica al insight de Lonergan.

${ }^{24}$ E. Coreth, "Immediacy and Mediation of Being...", p. 38. 
Emerich Coreth y aunque se me incluya junto con él cuando se menciona a los tomistas trascendentales, con todo, en el asunto de la prioridad de la metafísica hemos estado en desacuerdo, lo hemos hecho públicamente, y todavía estamos en desacuerdo. Estoy muy dispuesto a conceder que en una filosofía que se interesa primariamente en los objetos, la metafísica deba ser la ciencia primera, porque los objetos de la metafísica son los más básicos y universales. Pero en una filosofía que no se interese primariamente en los objetos sino en las operaciones, la metafísica no puede ser la ciencia primera. Lo que ahora es a la vez lo más básico y más universal lo son las operaciones, y estas se estudian en la teoría de las operaciones cognoscitivas. En segundo lugar viene el asunto de la validez de las operaciones, y tal es el interés de la epistemología. Solo en tercer lugar surge la cuestión de los objetos, que es el interés de la metafísica. ${ }^{25}$

La diferencia esencial entre la concepción de Lonergan y la de Coreth puede describirse en los siguientes términos: para Coreth, la metafísica pone de manifiesto el horizonte absoluto del ser como condición de posibilidad de toda realización espiritual humana. Para Lonergan, en cambio, la metafísica solo coincide con el "polo objetivo", y es necesario sacar a la luz de una manera explícita el "polo subjetivo", el cual se encuentra en la misma realización cognoscitiva del hombre. Por eso Lonergan escribe: "Yo no consideraría equivalente la metafísica con el horizonte total y básico [...]. La metafísica, en cuanto trata sobre el ser es equivalente con el polo objetivo de este horizonte; pero la metafísica, en cuanto ciencia, no es equivalente con el polo subjetivo". ${ }^{26}$

Ahora bien, mientras que Lonergan señala que Coreth, en su $\mathrm{Me}$ tafísica, no considera al hombre concreto, sino que lo subsume en la esfera total del ser, ${ }^{27}$ Coreth declara que Lonergan corre el riesgo de separar demasiado sujeto y objeto, como lo hizo la filosofía moderna. ${ }^{28}$ Es más, Coreth pregunta: “¿Y no es precisamente en una metafísica trascen-

${ }^{25}$ Bernard Lonergan, "Philosophy and the Religious Phenomenon" pp. 393-94, citado por Francisco Galán, “¿Qué es hacer metafísica según el Insight de Lonergan?”, Gregorianum 85, 4, 2004, pp. 760-761.

${ }^{26}$ Bernard Lonergan, "Metaphysics as Horizon...", p. 219.

${ }^{27}$ Loc. cit.

${ }^{28} C f r$. E. Coreth, "Immediacy and Mediation of Being...", p. 39. 
dental que este dualismo debe ser superado siendo trascendido y comprendido sobre las bases de un común fundamento originante?". ${ }^{29}$

Acerca de esta problemática, G. Sala, estudioso del pensamiento de ambos autores, anota las siguientes consideraciones: la observación que Coreth hace a Lonergan sobre la dualidad de sujeto y objeto no es consistente. Coreth la formula porque entiende el problema de la objetividad como el conocimiento del objeto por un sujeto. Para Lonergan, en cambio, el problema de la objetividad es simplemente la cuestión sobre cómo conocemos el ser. Si el ser es conocido a través del juicio, entonces por el juicio se conoce tanto el objeto como el sujeto. Así pues, la dualidad de sujeto y objeto queda superada en la unidad superior del ser y no es necesaria la metafísica trascendental que propone Coreth para superarla. ${ }^{30}$

A esta interpretación de G. Sala se le podría hacer esta observación: ¿por qué, entonces, Lonergan habla de la explicitación del polo subjetivo, en cuanto que es necesario sacar a la luz la teoría del conocimiento y la epistemología ya operantes en el sujeto, y no lo integra más bien en la totalidad del horizonte del ser, en la metafísica, a la cual considera solo como el polo objetivo? G. Sala, defendiendo la doctrina de Lonergan, responde que en el sujeto no solo existe la metafísica latente sino también un conjunto de factores que impiden que esta se lleve a cabo. Por eso:

Es necesario un análisis crítico del polimorfismo de la conciencia humana. Esta es aquella consideración más amplia del polo subjetivo que no es tarea de la metafísica. Pero, como se ve, no se trata de un horizonte más amplio -más allá del horizonte trazado por nuestra intencionalidad no hay nada-. Se trata más bien de pasar de una consideración más abstracta a una consideración más concreta del polo subjetivo, de un principio a un hecho. ${ }^{31}$

Si la interpretación de G. Sala es adecuada, considero que resulta inútil y confuso hablar de un polo subjetivo y un polo objetivo. Quizá sería

${ }^{29}$ Loc. cit.

${ }^{30} \mathrm{Cfr}$. Giovanni Sala, "Immediatezza e mediazione della conoscenza dell'essere. Riflessioni sull'epistemologia di E. Coreth e B. Lonergan”, Gregorianum 53, 1972, pp. 49-50.

${ }^{31}$ Ibid., p. 55. 
más conveniente decir que, dentro del horizonte total del ser, es necesario realizar un análisis más detallado y concreto de las estructuras cognoscitivas que permiten al hombre acceder correctamente al conocimiento del ser o bien de aquellos otros deseos que impiden el despliegue del conocimiento.

Pues bien, aunque Coreth reconoce que Lonergan lo ha superado en cuanto al empleo del análisis fenomenológico, ${ }^{32}$ no considero que las aclaraciones de G. Sala libren a Lonergan de la dualidad entre sujeto y objeto que Coreth le señala.

Con todo, los respectivos conceptos de metafísica no son suficientes en sí mismos, pues ambos autores remiten explícitamente al método y punto de partida adecuados que permitan realizar concretamente el concepto afirmado. Por tanto, debemos ocuparnos del método y punto de partida de la metafísica de ambos pensadores.

\section{Método y punto de partida de la metafísica}

\section{Lonergan}

El método

Si la metafísica explícita es el resultado del isomorfismo entre el conocer y lo conocido; si es posible solo porque antes es implícita o latente, entonces es fundamental buscar el método adecuado para realizarla; este sacará a la luz las condiciones de posibilidad de la metafísica:

Para llegar al conocimiento del ser en cuanto ser, debemos remontarnos hacia atrás, antes de todo contenido de las concepciones particulares, $\mathrm{y}$ antes de los juicios correspondientes, para poner en relieve la orientación dinámica del conocimiento inteligente y racional hacia un objetivo ilimitado. $^{33}$

${ }^{32}$ Cfr. E. Coreth, "Immediacy and the Mediation of Being...", p. 37.

${ }^{33}$ Giovanni Sala, "La métaphysique comme structure heuristique selon Bernard Lonergan", ArPh 33, 1970, p. 51. 
El método trascendental toma características propias al ser utilizado por Lonergan; este lo concibe como una introspección sobre la actividad del conocimiento, a fin de poner al descubierto las condiciones previas que lo hacen posible; en este punto se manifiesta claramente la influencia marechaliana, en cuanto que Lonergan parte de la subjetividad para llegar a la afirmación de la objetividad. Andrew Beards lo explica de en los siguientes términos:

Desde que la mente humana es la que produce, refina, revisa, acepta, modifica y rechaza los esquemas lógicos, las teorías científicas, las explicaciones históricas y las opiniones que mantenemos en la vida diaria, es la operación consciente de la mente la que constituye el "método" fundamental. ${ }^{34}$

Lonergan descubre que el conocimiento es un conjunto de actividades. En primer lugar, se presenta el nivel de lo sensible; este se constituye por la presentación de los datos a la conciencia. Los datos sensibles son incuestionables, simplemente se dan: es lo que Lonergan llama objetividad experiencial. Ahora bien, el ser humano no se conforma con la mera presentación de datos empíricos, sino que busca comprender lo que las cosas son. Por este motivo, la inteligencia humana reelabora los datos sensibles y los ordena en imágenes o esquemas; en seguida hace surgir de sí misma preguntas para cuestionar a los datos; estas preguntas son ¿Qué es esto? ¿Por qué? ¿Qué tan frecuentemente ocurre? De esta manera se desencadena la investigación sobre los datos. La investigación tiene como meta la comprensión inteligente de los datos, y esta se realiza mediante el acto del insight, es decir, mediante la intelección que descubre y agrega la inteligibilidad a lo meramente empírico. El acto del insight no es una mera "visión" dentro de los datos; es un acto fundamental y constitutivo de la inteligencia humana. Una vez que, a través de, y en los datos sensibles, se ha comprendido lo que la cosa es, la inteligencia produce un concepto; este es expresado por la palabra.

${ }^{34}$ Andrew Beards, Method in Metaphysics: Lonergan and the Future of Analytical Philosophy, Toronto, University of Toronto Press, 2008, p. 21. 
Nuevamente, el ser humano no agota su actividad de conocer en la comprensión de los datos, sino que se propone conocerlos con validez absoluta. Por ello, la inteligencia levanta nuevamente preguntas, pero ahora para la reflexión: ¿Es realmente así lo que he entendido? ¿Esto es verdaderamente así? Las preguntas para la reflexión tienen como meta provocar la realización del juicio. A través del juicio se conoce el ser. Para Lonergan, el juicio no es una mera síntesis, es decir, unión de conceptos, sino la absoluta "puesta" de esa síntesis en la realidad. ${ }^{35}$ Un juicio de este tipo es posible solo si se concibe, dice Lonergan, como un incondicionado virtual, ${ }^{36}$ esto es, como un juicio que tiene condiciones para su validez, y que, de hecho, esas condiciones han sido cumplidas: el juicio condicionado pasa a ser un incondicionado virtual o un absoluto de hecho. Lo que hace que el juicio condicionado, como mera síntesis mental, pase a ser virtualmente incondicionado, como síntesis real, es la emergencia de un insight reflejo sobre la experiencia, sobre los datos empíricos: ellos garantizan el cumplimiento de las condiciones requeridas para la absoluta "puesta" de la síntesis judicativa. En este nivel de la actividad de conocimiento se da la objetividad absoluta, la cual está legitimada por la objetividad experiencial de lo sensible y la comprensión de la inteligencia. La noción de objetividad absoluta confirma la inteligibilidad intrínseca del ser, de acuerdo con la cual el conocimiento humano conoce siempre, en cada uno de sus actos, el ser.

La objetividad coincide con la intencionalidad humana, y ambas se dirigen al ser y a la realidad, pues "conocimiento en sentido propio es conocimiento de la realidad o, más completamente, que el conocimiento es intrínsecamente objetivo, que la objetividad es la intrínseca relación de conocer y ser, y que ser y realidad son idénticos". ${ }^{37}$ Según Lonergan, todos los actos del conocimiento son conscientes e intencionales; al ser conscientes, el sujeto se encuentra presente a sí mismo en cuanto sujeto, en cuanto origen de las actividades realizadas; al ser intencionales, el

${ }^{35}$ Cfr. Insight, p. 436; Bernard Lonergan, "Insight: Preface to Discussion”, en F. E. Crowe, Collection, p. 160.

${ }^{36} \mathrm{El}$ incondicionado virtual se distingue esencialmente del incondicionado formal o absoluto, que Lonergan identifica con Dios.

${ }^{37}$ Bernard Lonergan, “Cognitional Structure”, en F. E. Crowe, Collection, p. 228. 
sujeto está presente a sí mismo, se descubre tendiendo hacia los objetos, como al contenido de sus actos cognoscitivos. Por lo tanto, la subjetividad incluye la objetividad y la objetividad incluye la subjetividad:

Parecería que, aunque el punto de vista de Lonergan es el polo subjetivo de la polaridad ser-conocer, aun este punto de vista envuelve desde el principio una completa aceptación del polo objetivo en sí mismo y no simplemente como un reflejo o correlato del polo subjetivo. Lonergan ha tenido éxito en la tarea tomada por Maréchal, la tarea de aceptar el cambio de polo kantiano y todavía afirmar la centralidad del polo objetivo. ${ }^{38}$

Al término del análisis del conocer y su realización concreta en las matemáticas, las ciencias y el sentido común, Lonergan afirma que el conocimiento es una estructura formalmente dinámica.

Pero aún queda por aclarar una ulterior noción de objetividad, que Lonergan llama objetividad normativa; esta saldrá a la luz solamente si el ser humano se da a la tarea de conocer su conocer, es decir, de objetivar sus operaciones conscientes y hacerlas objetos intencionales de su estructura dinámica de conocer; con el fin de tomar conciencia de su propio dinamismo. Lonergan llama a este proceso autoapropiación; esta es la meta del método trascendental en cuanto introspección.

La autoapropiación no es una simple conciencia de sí mismo y de sus operaciones, consiste más bien en una reduplicación de la estructura dinámica del conocimiento. Francisco Galán lo explica de la siguiente manera:

Si conocer es 1) experimentar, 2) entender y 3) juzgar, conocer lo que es el conocimiento implica: I) experimentar lo que es experimentar, entender y juzgar; II) entender lo que es experimentar entender y juzgar; y III) juzgar si lo entendido en II es verdadero o no. El método trascendental en sentido amplio es 1, 2 y 3 , en sentido específico es la duplicación de la estructura (I, II y III), la autoapropiación de lo que desde siempre hacemos al conocer. ${ }^{39}$

${ }^{38}$ N. D. O'Donoghue, “Lonergan's Notion of Being in Relation to his Method", en P. Corcoran (ed.), Looking at Lonergan's Method, 1975, Dublín, The Talbot Press, p. 47.

${ }^{39}$ Francisco Galán, “¿Qué es hacer metafísica según el insight de Lonergan?”, p. 762. 
En este proceso de autoapropiación, el sujeto dispone de una percepción muy peculiar:

En el caso del método trascendental introspectivo, tenemos el ejemplo primario de la presencia dual del sujeto, del sujeto simultáneamente siendo conocido dos veces, ya que en cada acto del proceso de objetivación el sujeto está presente a sí mismo y se conoce como sujeto a través de la (aumentada) conciencia; al mismo tiempo está presente a sí mismo y se conoce como objeto por la intencionalidad. ${ }^{40}$

Obtenida la autoapropiación a través de un constante y personal esfuerzo, Lonergan cae en la cuenta de que la conciencia intencional no es un elemento meramente psicológico, sino un constitutivo esencial del ser humano; por la conciencia el hombre es capaz de trascender el mundo sensible y de trascenderse a sí mismo:41 "Conscientemente, inteligentemente, racionalmente (la intencionalidad) va más allá: más allá de los datos a la inteligibilidad; más allá de la inteligibilidad a la verdad y a través de la verdad al ser; y más allá de la verdad y el ser conocidos a la verdad y el ser aún por conocer". ${ }^{42}$

Con la autoapropiación de la conciencia, se obtiene finalmente la noción parcial de objetividad normativa, pues al autoapropiarse de su conciencia intencional, inteligente y racional, el ser humano descubre que la inteligencia actúa y se desarrolla según sus propias leyes; estas norman y determinan todo la actividad consciente del hombre. A la luz de esta explicación, se comprende claramente la expresión que resume el intento lonerganiano en Insight:

Comprende cabalmente lo que es comprender, y así no solo habrás de comprender los lineamientos esenciales de todo lo que hay por comprender, sino también tendrás una base firme, un modelo invariante, abierto a todos los desarrollos posteriores de la comprensión. ${ }^{43}$

${ }^{40}$ Walter E. Conn, “Transcendental Analysis of conscious subjectivity: Bernard Lonergan's Empirical Methodology”, The Modern Schoolman 54, 1977, p. 226.

${ }^{41}$ Ibid., p. 223.

${ }^{42}$ Bernard Lonergan, “Cognitional Structure...", p. 228.

${ }^{43}$ Insight, p. 31. 
La autoapropiación de la conciencia inteligente y racional justifica el isomorfismo entre la estructura del conocer y la estructura de lo conocido, y se justifica a sí misma por retorsión, ${ }^{44}$ ya que cualquier intento de negarla se realizaría con base en la estructura dinámica del conocer. Entonces, la metafísica explícita puede ser llevada a cabo como una ciencia rigurosa del ser proporcionado en sus características generales: 45 "La metafísica metódica, en su totalidad y en todo su detalle, no es otra cosa que el correlato de la teoría del conocimiento, y se sigue necesariamente del desarrollo de ésta". ${ }^{46}$

\section{El punto de partida}

Ahora bien, ¿cuál es el punto de partida de la conciencia inteligente y racional? ¿cuál es la fuente de la que mana todo su dinamismo intrínseco? El punto de partida tiene que ser algo primero e incuestionable, que se justifique a sí mismo como válido. Esta pregunta coincide con aquella sobre el a priori del conocimiento humano, en cuanto que este es anterior a toda experiencia posible y representa su condición de posibilidad.

Unos han puesto el punto de partida en la pregunta; ${ }^{47}$ con ella y en ella se inicia el proceso dinámico de conocer; produce el cambio de un nivel de conocimiento a otro al cuestionar los datos que vienen de la sensibilidad y al cuestionar la síntesis mental comprendida para descubrir su validez absoluta. Otros colocan el a priori en la estructura dinámica del conocer, ${ }^{48}$ en cuanto que tiende hacia el universo concreto del ser. Otros más, finalmente, colocan el punto de partida en algo

${ }^{44}$ Ya Aristóteles utilizaba esta "argumentación indirecta" para refutar a aquellos que negaban el principio de no contradicción. Aristóteles, Metafísica IV 31005 b 15-34. Véase también G. Isaye, "La justification critique par retorsion", Revue philosophique de Louvain, 52, 1954, pp. 205-33.

${ }^{45}$ Cfr. Giovanni Sala, "La métaphysique comme structure heuristique Selon Bernard Lonergan”, ArPh 33, 1970, p. 49.

${ }^{46}$ Op. cit., p. 448.

${ }^{47}$ Cfr. Giovanni Sala, "The A priori in the Human Knowledge: Kant's Critique of pure reason and Lonergan's insight", The Thomist 40, 1976, p. 187.

${ }^{48} \mathrm{Cfr}$. Giovanni Sala, "La métaphysique comme structure heuristique selon Bernard Lonergan", p. 444. 
mucho más anterior a la pregunta: el deseo puro, desinteresado e ilimitado de conocer, ${ }^{49}$ este deseo de conocer, dice Lonergan, subyace a toda realización del conocimiento humano como condición de su posibilidad:

La unidad de los niveles es una unidad dinámica, básicamente fundamentada en el deseo puro de conocer, aquel espíritu de curiosidad que levanta cuestiones y que es ilimitado en alcance. En las cuestiones que levanta o puede levantar, intenta el universo del ser mismo, aquel que puede ser conocido a través de una totalidad de juicios. ${ }^{50}$

Ahora bien, este deseo de conocer es pura tendencia hacia su objetivo; por esta razón Lonergan afirma que el deseo de conocer constituye la noción heurística de ser: el ser es el objetivo del deseo de conocer; ${ }^{51}$ es la anticipación del contenido de todos los actos cognoscitivos y este contenido es el universo del ser. Esto confirma una vez más la inteligibilidad intrínseca del ser, de lo real: "nuestra definición de la realidad es solamente heurística, es decir, se expresa en los términos del proceso por el cual la conocemos [...] decimos solamente que, cuando nuestro deseo de conocer se actúe de hecho en un conocimiento, esto que conocemos es el ser". 52

Además, si el deseo de conocer es inteligente e ilimitado, su objetivo, es decir, el ser, será igualmente inteligible e ilimitado. Según esto, el deseo de conocer es el punto de unión entre la subjetividad y la obje-

49 “Al objetivo de tal deseo [Lonergan] le llama noción de ser. Le llama noción y no mera tendencia u orientación, porque se hace consciente. Viene a ser algo a priori, pero no como un a priori de contenido, sino de la orientación del funcionamiento de nuestra estructura dinámica cognoscitiva. Esta noción es trascendental (se entiende aquí en el sentido escolástico como contrapuesto a lo categorial-conceptual-cultural), irrestricta y subyace y penetra absolutamente todo contenido cognoscitivo”. Francisco Galán, “¿Qué es hacer metafísica según el insight de Lonergan?", p. 763.

${ }^{50}$ James L. Marsh, "Lonergan's Mediation of Subjectivity and Objectivity”, The Modern Schoolman 52, 1975, p. 254.

${ }^{51}$ Insight, p. 348.

${ }^{52}$ Giovanni Sala, "La métaphysique comme structure heuristique selon Bernard Lonergan", p. 556. Cfr. también Insight, p. 583: "si por el ser se entiende el objetivo del deseo puro de conocer $[\ldots]$, entonces debemos afirmar la inteligibilidad intrínseca del ser". 
tividad, entre la tendencia del sujeto, conocimiento ex parte subjecti, y el objetivo de esa tendencia, conocimiento ex parte objecti. ${ }^{53}$ Por ello en el deseo de conocer se percibe claramente una síntesis a priori: el sujeto está, en virtud de su dinamismo intrínseco, esencialmente orientado hacia el ser en su totalidad; el deseo de conocer, en cuanto intentio intendens, se actualiza en cada una de las realizaciones particulares del conocimiento humano, en cuanto intentio intentae. Además, en virtud de la orientación ilimitada del deseo de conocer, se justifica la pretensión de validez absoluta que se alcanza en el juicio. ${ }^{54}$

Por lo tanto, la introspección por la cual se ponen de manifiesto las condiciones de posibilidad de la actividad cognoscitiva humana y sus alcances, es una introspección trascendental; esta es, en cierto sentido, un modo de la reducción trascendental, puesto que a partir del hecho del conocimiento Lonergan se remonta a las condiciones que lo hacen posible. Sin embargo, esta consideración del método trascendental difiere esencialmente de la de Kant. Este toma como punto de partida las condiciones de posibilidad de nuestro conocimiento de los objetos, mientras que Lonergan inicia por la consideración de las mismas actividades que forman el conocimiento, para captarlas en su originalidad y posibilidad. Es un punto de arranque más radical que en $\mathrm{Kant}^{55}$. El método trascendental no se agota en la mera consideración acerca del conocimiento de los objetos por parte del sujeto, sino que va más allá: "el análisis trascendental se concluye solamente cuando, yendo más allá de las condiciones formales de acuerdo con las cuales la sensibilidad recibe las impresiones y el entendimiento piensa los contenidos de la intuición, llega al sujeto que realiza todas esas acciones". ${ }^{56}$

${ }^{53} \mathrm{Cfr}$. Giovanni Sala, "La métaphysique comme structure heuristique selon Bernard Lonergan", p. 57.

${ }^{54}$ Ibid., p. 49.

${ }^{55}$ Cfr. Otto Muck, The Transcendental Method, 1968, Nueva York, Herder and Herder, trad. de W. D., Seidensticker, pp. 274-5.

${ }^{56}$ Giovanni Sala, "The A Priori in the Human Knowledge: Kant's Critique of Pure Reason and Lonergan's insight", The Thomist 40, 1976, p. 211. 


\section{Coreth}

El método

Coreth ha establecido claramente que la metafísica es la ciencia que busca explicitar nuestro conocimiento originario acerca del ser del ente. La realización de esta explicitación requiere un punto de partida primero e incuestionable y exige también un método adecuado. ¿Cuáles son estos?

Respecto al método, Coreth subraya su importancia, sobre todo en vistas de la fundamentación de la metafísica y su connatural aspiración por adquirir un estatuto científico legítimo: "puesto que es esencial a toda ciencia no solo el que se desarrolle metódicamente, sino también el que esté cierta de la justeza de su método, el resultado del conocimiento científico queda mediado por el método". ${ }^{57}$

Con este texto, Coreth pone de manifiesto la característica esencial del método que conduce a la realización de la metafísica como verdadera ciencia, a saber: "la mediatez como principio fundamental del conocimiento metafísico". ${ }^{58}$ Esta mediatez viene exigida por el objeto mismo de la metafísica, ya que el objeto de toda ciencia, de suyo y primariamente, condiciona el método que debe seguirse. Así, el objeto de la metafísica condiciona el método apropiado para autoconstituirse de manera refleja y crítica. Pero el objeto de la metafísica no es algo empíricamente dado de manera directa. La metafísica no pregunta por un ente particular o por un campo determinado de entes, sino por el ente en cuanto tal, esto es, por lo que caracteriza al ente en cuanto que es, por lo más fundamental del ente: el ser del ente. Este objeto de la metafísica, que no se muestra directamente en la experiencia sensible, solamente es alcanzado por la mediación del pensar metafísico.

El conocimiento del objeto del que se parte es solamente un presaber del objeto, atemático e implícito, que está presente en todo el actuar consciente del ser humano. Este presaber del objeto media el método adecuado para la reflexión acerca de sí mismo, con el fin de llegar a un

${ }^{57}$ Metafísica, p. 43.

${ }^{58}$ Ibid., p. 47. 
conocimiento explícito, reflejo y conceptual del objeto de la metafísica, es decir, el ser del ente. Hildegard Anegg comenta al respecto que:

Indicador para su determinación metódica de la relación entre ser y saber es la intuición hegeliana de identidad y diferencia. También la teoría de la inmediatez mediada tiene una importancia central y se desarrolla en una metafísica que ve la relación entre ser y ente como un continuo proceso de mediación. ${ }^{59}$

Por tanto, en la misma medida en que el objeto de la metafísica se vaya aclarando y definiendo, saldrán a la luz las características esenciales del método que le es propio. En otras palabras, el método de la metafísica se autojustifica a partir de la autofundamentación metódica de la misma. Por eso Coreth afirma: "de aquí se sigue que la determinación refleja y crítica del método de la metafísica coincide sencillamente con la autofundamentación objetiva (sachlichen) de la metafísica". ${ }^{60}$

Para Coreth, objeto y método de la metafísica se condicionan mutuamente. Esto garantiza la fundamentación crítica y refleja de la metafísica como ciencia. Efectivamente, Coreth parte de un conocimiento inmediato que, por ser tal, es atemático, implícito, irreflejo, y que por la mediación de la realización metódica del pensar metafísico llega a ser un conocimiento explícito, reflejo y conceptual.

Para ello es preciso demostrar, más exactamente mostrar, puesto que se habla de saber originario, que en cada realización metafísica del pensar se da la evidencia de un presaber atemático e implícito que es condición de posibilidad de la realización misma. Ahora bien, el método que está concernido por las condiciones de posibilidad de cualquier realización cognoscitiva es, desde Kant, el método trascendental. Pero Kant no explotó toda la riqueza de este método y se quedó en la mera consideración sobre la forma en que el sujeto finito conoce los objetos. Con el fin de superar estos límites e ir más allá de Kant, Coreth asume el

${ }^{59}$ Hildegard Anegg, "Gelebte Metaphysik”-Metaphysik fur das Leben. Ein Beitrag zum Verständnis transzendental metaphysischen Denkens und Argumentierens, 2014, Innsbruck, tesis doctoral, p. 157.

${ }^{60}$ Ibid., p. 45. 
método trascendental para conducirlo hasta sus últimas consecuencias, como ya lo hiciera Maréchal. En este sentido Coreth escribe: "solamente si -contra Kant, y yendo más lejos que Kant- se pone de manifiesto que el saber originario a priori es un saber metafísico acerca del ser, y que ese primer saber descubre el horizonte incondicionado del ser en general, se puede fundamentar la metafísica crítica y metódicamente". ${ }^{61}$

Ese presaber originario acerca del ser puede ser alcanzado solo por medio del método trascendental. En este intervienen fundamentalmente dos movimientos complementarios: a) la reducción trascendental, que parte de la realización concreta y actual y pone de manifiesto las condiciones previas de su posibilidad; y b) la deducción trascendental, que parte de las condiciones de posibilidad develadas y pone al descubierto la estructura y necesidad de la realización. De la conjugación y combinación de estos movimientos resulta lo siguiente: el método trascendental permite partir de la realidad, es decir, de la realización concreta que el hombre lleva a cabo conscientemente, y permite también regresar a la realidad, habiéndola justificado críticamente, esto es, habiendo puesto de manifiesto la estructura esencial necesaria de esa realización. Por tanto, el método trascendental es realista y objetivo.

Por esta razón, Coreth afirma que el método trascendental es el método fundamental e integral, único capaz de constituir la metafísica crítica y sistemáticamente. "El método trascendental queda constituido conforme a su esencia, en la mediación de la inmediatez. Tiene que mediar el conocimiento inmediato atemático para convertirlo en temático". ${ }^{62}$

Ahora bien, ese presaber originario sobre el ser del ente, que está implícito en la realización misma del pensar metafísico consiste, expresado en categorías kantianas, en "contenidos objetivos metafísicamente universales y necesarios", ${ }^{63}$ los cuales son, igualmente según Kant, juicios sintéticos a priori. Por este motivo, según Coreth, el método adecuado a la metafísica debe propiciar la manifestación de una síntesis

${ }^{61}$ Ibid., p. 54.

${ }^{62}$ Ibid., p. 70.

${ }^{63}$ Ibid., p. 50. 
a priori. Y, efectivamente, el método trascendental, tal como lo propone Kant, propicia tal síntesis, en tanto que parte de la experiencia-los datos sensibles- para sacar a la luz su condición última de posibilidad en cuanto que conocidos por el sujeto; una vez que se descubre esta condición de posibilidad, se presenta la misma exigiendo una validez necesaria pero relativa al sujeto finito que conoce los objetos, y que, por tanto, no proviene de lo empírico, sino que es alcanzada por la inteligencia, esto es, a priori. Y entonces cada dato de la experiencia puede ser integrado en el conocimiento originario al que se ha llegado, puesto que este último es su condición de posibilidad, es decir, síntesis.

Sin embargo, Coreth, después de sus investigaciones históricas acerca del método trascendental, está convencido de que "la filosofía trascendental no necesariamente es solo crítica del conocimiento ni está ligada tampoco a una metafísica de la subjetividad, sino que puede acabar en el problema ontológico". ${ }^{64}$

Por tanto, afirma que el método trascendental, con sus movimientos complementarios de reducción y deducción, propicia la síntesis $a$ priori requerida. Pero supera la doctrina kantiana en cuanto que, por un lado, la reducción trascendental saca a la luz la condición última y absoluta de cualquier realización esencialmente humana, poniendo de manifiesto un prius que antecede a toda experiencia posible, pero que es condición de posibilidad de toda experiencia posible y que además reclama una validez absoluta y universal.

La diferencia radical entre el a priori kantiano y el corethiano consiste en que Kant lo concibe como una categoría puramente formal del sujeto que determina nuestra manera de conocer los objetos, mientras que Coreth busca afanosamente darle un contenido absoluto que garantice la validez universal y absoluta que se le atribuye. Con respecto a la cuestión del a priori, Coreth dice que "tiene que tratarse [...] de un prius que esté ya determinado en sí mismo en cuanto al contenido,

${ }^{64}$ Otto Muck, "La escuela marechaliana de lengua alemana. La filosofía trascendental como metafísica: J. B. Lotz, K. Rahner, W. Brugger, E. Coreth y otros”, en Emerich Coreth et al. (ed.), Filosofia cristiana en el pensamiento católico de los siglos XIX Y XX, p. 560. 
y que por lo tanto pueda llegar a ser en sí mismo objeto del conocimiento inmediato". ${ }^{65}$

Su validez universal y absoluta solo puede mostrarse si se pone de manifiesto que el pensamiento se mueve desde siempre en el campo metafísico, si ya desde siempre el pensamiento está cabe el ser, si "nuestro pensamiento se mueve esencialmente en el horizonte del ser". ${ }^{66}$ Sin embargo, la clara manifestación de la síntesis a priori, tal como la entiende Coreth, saldrá a la luz solo al final de la reducción trascendental sobre el punto de partida.

\section{El punto de partida}

Coreth asumió la tarea de descubrir y legitimar el punto de partida de la metafísica, ya que tanto sus primeros profesores J. de Vries ${ }^{67}$ y J. B. Lotz ${ }^{68}$ influidos ambos por J. Maréchal, ${ }^{69}$ como sus posteriores influencias Martín Heidegger (1889-1976) ${ }^{70}$ y Karl Rahner (1904-1984), ${ }^{71}$ se esforzaron por poner de manifiesto la evidencia primera y originaria que permitiera fundamentar la metafísica crítica y metódicamente. Así pues, Coreth afirma que el punto de partida de la metafísica tiene que serlo en sentido estricto, es decir, que no presuponga nada en absoluto y que se justifique a sí mismo como válido.

${ }^{65}$ Metafisica, p. 58.

${ }^{66}$ Ibid., p. 52.

${ }^{67}$ De Vries, en su obra Pensar y ser, toma como punto de partida la conciencia, a ejemplo de Agustín o Descartes.

${ }^{68}$ Lotz, siguiendo a Maréchal, pone en el análisis del juicio el punto decisivo para la realización de la metafísica, como es manifiesto en su Metaphysica operationis humanae.

${ }^{69}$ Precisamente, la obra principal de Maréchal lleva por título El punto de partida de la metafísica. Maréchal afirma que es el juicio el punto de partida más radical, puesto que ahí se da una afirmación de carácter absoluto. Esta afirmación, que parte de la experiencia, pero que trasciende la experiencia supera esencialmente la problemática trascendental kantiana, por medio del mismo método de Kant. Esta línea de pensamiento será tomada por Coreth, aunque no acepte el juicio como punto de partida.

${ }^{70}$ Heidegger afirma la importancia de colocar al principio de la reflexión metafísica la pregunta por el ser, sobre todo en su obra principal Ser y tiempo.

${ }^{71}$ Su obra Espíritu en el mundo señala también, siguiendo y superando a Heidegger, a la pregunta por el ser como inicio de la reflexión trascendental. 
Al comienzo de la metafísica lo único que el hombre tiene es la pregunta por el punto de partida de la metafísica y la pregunta por su legitimidad como verdadero principio y fundamento. Ahora bien, los puntos de partida surgidos a lo largo de la historia del filosofar, a saber, la conciencia, la duda, el juicio, la pregunta por el ser, no son absolutamente primeros, sino que presuponen ya algún contenido empírico; además no pueden legitimarse a sí mismos, porque aún pueden ser cuestionados acerca de su validez como principio.

Según Coreth, en la pregunta misma por el punto de partida está la respuesta: la pregunta es el punto de partida. Efectivamente, la pregunta ofrece todas las características que han sido requeridas para constituirse en punto de partida legítimo. La pregunta no presupone nada en absoluto, sino que es expresión y manifestación del deseo de saber, y puede legitimarse a sí misma como válida, en cuanto que, si es cuestionada por su legitimidad, la pregunta queda puesta nuevamente. La pregunta por el punto de partida es el punto de partida más radical y originario. Es legítimamente principio y fundamento, capaz de soportar sobre sí y mediar el ulterior desarrollo metódico de la metafísica.

La justificación de la pregunta como punto de partida se realiza por medio de la retorsión, ya que si se pregunta por su validez y legitimación, la realización del acto de preguntar anula el sentido explícito de la pregunta; a partir de la realización del preguntar se afirma implícitamente lo que se niega explícitamente.

Ahora bien, si la pregunta es el punto de partida, la pregunta debe mostrar ese saber previo e implícito que es condición de posibilidad de toda realización; esto es, debe mostrar que el hombre está siempre en el ser, que todas sus actividades conscientes se llevan a cabo en el horizonte absoluto del ser. La pretensión de Coreth es mostrar que, efectivamente, la pregunta es capaz de mostrar tal horizonte puesto que

el "objeto" de la metafísica, tal como aparece primaria aunque atemáticamente en la misma pregunta metafísica -en cuanto condición de posibilidad-determina el método fundamental de la metafísica, la 
reflexión trascendental sobre la pregunta misma, que pone de manifiesto un presaber acerca del ser del ente como condición de su posibilidad..$^{72}$

La pregunta por el punto de partida no supone nada y puede legitimarse a sí misma como principio. Con todo, puede ser puesta nuevamente en cuestión, ya no en cuanto pregunta por el punto de partida sino en tanto que pregunta. De esta manera se propicia la consideración sobre sus condiciones de posibilidad; así, la pregunta por el punto de partida de la metafísica, se convierte en pregunta por la pregunta o pregunta por las condiciones de posibilidad de la pregunta en cuanto pregunta. Esto es, en definitiva, la pregunta trascendental. ${ }^{73}$ "La pregunta efectúa necesariamente -como consecuencia de su interrogaciónla reflexión sobre sí misma y se convierte en pregunta acerca de la pregunta. El tomar la pregunta como punto de partida media el método para interrogar de manera trascendental a la realización de la pregunta". ${ }^{74}$

¿Cómo es posible la pregunta en cuanto pregunta? Solo es posible si se tiene un presaber atemático e implícito acerca de la realización de la pregunta; solo es posible si existe un presaber originario que sabe de sí mismo y por eso la pregunta puede ser planteada y planteada con sentido completo; y si, al mismo tiempo, ese presaber, que está con-puesto y con-realizado en la misma realización de la pregunta, es un cierto no-saber, pues de otra manera la pregunta quedaría superada por el saber: ya no habría que preguntar por nada. Ese presaber es, pues, un saber que no sabe, o un no-saber que sabe: surge así una dialéctica en el interior del presaber que es condición de posibilidad de la pregunta en cuanto pregunta.

${ }^{72}$ Metafisica, p. 47.

${ }^{73}$ Según Coreth, la pregunta trascendental está presente desde los albores de la filosofía griega misma, en cuanto que al preguntar por los fundamentos últimos de todas las cosas (el arché), estaban ya trascendiendo el campo de lo meramente dado. Con todo, es a partir de Kant cuando se toma plena conciencia que el conocimiento tiene condiciones a priori. Cfr. E. Coreth, "Immediacy and Mediation of Being...", p. 34.

${ }^{74}$ Metafisica, p. 60. 
Esta dialéctica se lleva a cabo entre concepto y realización, ya que lo expresado temáticamente en conceptos no agota el presaber atemático que está con-puesto en la realización de la pregunta como condición de su posibilidad: de otro modo ya no se podría seguir preguntando. "El ser se revela a esta pregunta como condición de su posibilidad; pues todo preguntar es un preguntar por el ser, al que siempre conocemos $\mathrm{y}$ al que tenemos que interrogar una y otra vez, sin poderlo alcanzar nunca en un saber conceptual". ${ }^{75}$

Además de lo anterior, es necesario ahondar en el contenido y sentido de ese presaber originario que está siempre implícito en toda realización consciente humana. Así pues, Coreth continúa con la aplicación de la reducción trascendental a la pregunta, a fin de llegar hasta la condición última y radical de su posibilidad.

Toda pregunta tiene un presaber previo como condición de su posibilidad. Pero ese presaber se da en varios niveles. Así, el hombre tiene un presaber que entra en la pregunta particular pero no como condición de posibilidad sino solamente para determinar el sentido preciso de la pregunta. Tal presaber es llamado por Coreth con-saber modificativo. Cada pregunta tendrá, además, un presaber constitutivo atemático como condición de su posibilidad. Finalmente, en toda pregunta se parte de lo ya sabido hacia lo no sabido todavía.

Cada pregunta particular tiene un presaber constitutivo que la hace precisamente esta pregunta particular. Ese presaber trasciende lo ya sabido empíricamente y anticipa la posible respuesta empírica a la pregunta. De tal manera que la pregunta particular tendrá un presaber propio. Sin embargo, la pregunta por la pregunta no puede estar determinada por ningún presaber particular, sino únicamente por el puro presaber: este será condición de posibilidad del preguntar, en cuanto trascendencia pura de la ya sabido, de otro modo la realización del preguntar agotaría el presaber y la anticipación pura de lo no sabido. ${ }^{76}$

Coreth pregunta, por el alcance del preguntar, por el campo que puede ser cubierto con la anticipación pura que se con-pone en la

${ }^{75}$ Ibid., p. 73

${ }^{76}$ Ibid., p. 96. 
realización de la pregunta. Y, una vez más, la misma pregunta da la respuesta exacta. Si pregunto por los límites del preguntar, la realización del preguntar ha rebasado ya cualquier límite posible: se puede preguntar por todo. Si pregunto por lo preguntable en general, se descubre temática y explícitamente el horizonte ilimitado de lo preguntable en general. De modo que el presaber originario, que es condición de posibilidad de la pregunta, se descubre como la anticipación del horizonte ilimitado para la realización del preguntar. ${ }^{77}$ Por tanto, el presaber de la pregunta se ofrece como aquello que constituye el horizonte de la pregunta en tanto que a priori.

Así pues, cuando se pregunta por lo interrogable en general se descubre un presaber puro en la trascendencia pura de lo ya sabido y en la proyección o anticipación pura de lo no sabido: "La pregunta acerca de la pregunta, en cuanto pregunta, es por lo tanto la pregunta acerca del puro presaber de la pregunta en general". ${ }^{78}$

Este presaber puro es atemático y está con-puesto en la misma realización del preguntar; pero esto no quiere decir que sea algo vacío o puramente formal, sino que tiene un contenido ya determinado. El contenido del presaber es el horizonte de lo interrogable en general: abarca todo aquello por lo que el hombre pueda preguntar actual o virtualmente. Para ahondar en el contenido del presaber, Coreth se pregunta si es posible preguntar de una sola vez por la totalidad de lo preguntable, esto es, si se puede preguntar por el concepto o categoría que abarque todo lo interrogable en unidad, ya que "la unidad de la pregunta supone la unidad de lo preguntado". ${ }^{79}$ Coreth responde afirmativamente y declara que "todo aquello por lo que puedo preguntar y en cuanto que puedo preguntar por ello, tiene su unidad: que es. Pero a todo aquello que es, llamamos ente". ${ }^{80}$

Por lo tanto, el ente en general es el "hacia dónde" de la anticipación pura del presaber puro de la pregunta en cuanto pregunta.

${ }^{77}$ Nótese que, ya desde estas primeras aproximaciones el horizonte de realización no es puramente formal, sino que posee contenido, en cuanto que posibilita la realización concreta y actual del preguntar, del cual se ha partido para sacar a la luz sus condiciones de posibilidad.

${ }^{78}$ Ibid., p. 96.

${ }^{79}$ Ibid., p. 101.

${ }^{80}$ Loc. cit. 
Pero puede ahondarse aún más en el contenido del presaber, toda vez que puedo preguntar por la totalidad de los entes de una sola vez, es decir, preguntar por lo que hace del ente ente, por el fundamento que unifica a todo ente; y si el ser es aquello en lo que todo ente coincide y encuentra su unidad, Coreth concluye que "la anticipación pura se dirige al ser de todo ente. El presaber acerca del ser es la condición de posibilidad del preguntar en general". ${ }^{81}$

Toda realización particular del preguntar tiene su condición de posibilidad en el presaber puro acerca del ser, en cuanto que el ser trasciende a todo ente y a toda pregunta, y en cuanto que el ser anticipa toda posible respuesta, ya que cualquiera que esta sea es en virtud del ser.

La anticipación pura de la pregunta en cuanto pregunta no se dirige hacia el ente en particular, sino hacia el ser en su totalidad, es decir, hacia el puro horizonte, solo dentro del cual se puede preguntar por el ente en particular y se le puede conocer. ${ }^{82}$

El ser como horizonte es condición de posibilidad del preguntar en general solo si y en la medida en que es el fundamento de la interrogabilidad, esto es, se sabe ya algo acerca del ser, y de la cuestionabilidad, es decir, no se conoce todo del ser. Ahora bien, si la realización del preguntar tiene como condición última de posibilidad un presaber acerca del ser, y el ser se presenta como pura interrogabilidad, el preguntar por el ser es esencialmente necesario. ${ }^{83}$

Por otra parte, la pregunta por el ser busca una validez universal y necesaria, ilimitada e incondicionada. Efectivamente, en cuanto que el ser como horizonte trasciende desde siempre lo condicionado, es decir, los entes, tiene una validez incondicionada, que no puede ser ya trascendida. Esto significa que todos aquellos que descubren el ser como horizonte descubren también su inherente exigencia de validez incondicionada.

${ }^{81}$ Ibid., p. 103

${ }^{82}$ Ibid., p. 105.

${ }^{83}$ El preguntar por el ser constituye la esencia misma del hombre. Cfr. Karl Rahner, Espíritu en el mundo. Metafísica del conocimiento finito según Santo Tomás de Aquino, 1963, Barcelona, Herder, obra refundida por J. B. Metz, tr. de B. A. Álvarez, pp. 73-77. 
El ser al que se ha llegado no es el ser colectivo, o sea, la suma de todos los entes, ni el ser como principio de todos los entes; es simplemente el ser como horizonte, esto es, como campo de posibilidad y de realización de todo ente.

Entonces "ser" significa no solamente el ser de los objetos, no solamente el reino de la objetividad posible. También significa el ser que nosotros mismos somos, esto es, el ser que nosotros mismos realizamos y experimentamos como el ser que pone lo que simplemente es u ocurre en su actualidad. ${ }^{84}$

La reflexión trascendental sobre la pregunta ha puesto de manifiesto al ser como horizonte incondicionado e ilimitado que posibilita toda realización. Sin embargo, en cuanto que el ser como horizonte se conpone y con-realiza en la misma realización, el ser se revela también como realización. La reducción trascendental sobre la pregunta ha puesto de manifiesto que en el ser como horizonte se realiza una síntesis a priori, es decir, la anticipación del ser por parte de la intención del sujeto. Y, en cuanto que la anticipación del sujeto se dirige hacia el ser en su totalidad, viene garantizada la pretensión de validez absoluta e incondicionada.

\section{Semejanzas}

Respecto al método utilizado para llevar a cabo la metafísica, una primera semejanza salta a la vista en el hecho que tanto Lonergan como Coreth asumieron el método trascendental, buscando llevarlo hasta sus últimas consecuencias; esto señala la influencia de Maréchal en ambos pensadores, ya que él fue el primero en tomar el método trascendental para "superar a Kant por medio de Kant".

Otra semejanza es que ambos utilizaron la retorsión para justificar la validez de su punto de partida: tanto el deseo de conocer de Lonergan como la pregunta de Coreth se legitiman nuevamente cuando son puestos

${ }^{84}$ E. Coreth, "Immediacy and Mediation of Being...", p. 41. 
en cuestión. Una tercera semejanza, la más importante, es que ambos filósofos llegaron al ser como condición última de posibilidad de toda realización intelectual humana. Por último, la cuarta semejanza radica en que ambos sacaron a la luz la síntesis a priori requerida por el método trascendental para llegar a la condición última de posibilidad; en efecto, el ser es aquello hacia lo que tiende formalmente la inteligencia humana, en el caso de Lonergan, mientras que en Coreth el ser constituye el horizonte absoluto de todos los objetos, previamente anticipado por la tendencia formal del sujeto.

\subsection{Diferencias}

Tomando nuevamente sus respectivos comentarios y críticas, se encuentran las siguientes diferencias. Respecto al método, Lonergan niega que el método trascendental sea el único posible para fundamentar la metafísica, como afirma Coreth; al contrario, el método trascendental no es sino un método más que debe ser integrado en una consideración trascendental de los métodos, a fin de alcanzar un punto de vista total: 85

Ya que latente en la realización del investigador encarnado no solamente hay una metafísica que revela el polo objetivo del horizonte total, sino también hay el método de realización que, tematizado y hecho explícito revela el polo subjetivo en su completa y propia estatura. ${ }^{86}$

Sin embargo, Coreth declara que el método trascendental saca a la luz las condiciones de posibilidad de los demás métodos, y pone de manifiesto la insuficiencia de los mismos para fundamentar crítica y sistemáticamente la metafísica.

Por esta razón, el método trascendental no es un posible método al lado de otros métodos científicos y filosóficos. Más bien, asume una prioridad fundamental porque él interroga todo con una consideración hacia

${ }^{85}$ Cfr. Bernard Lonergan, "Metaphysics as Horizon...”, pp. 219-20.

${ }^{86}$ Ibid., p. 220. 
su "prius", en orden a entender su "a priori"; él debe reflexionar críticamente sobre todo -incluyendo cada método- y debe trascenderlo con una consideración hacia sus presupuestos. ${ }^{87}$

Ahora bien, mientras que para Lonergan la doctrina trascendental de los métodos es anterior a la realización de la metafísica como ciencia, para Coreth la reflexión trascendental sobre los actos cognoscitivos, que saca a la luz sus condiciones últimas de posibilidad, es ya en sí misma metafísica. $^{88}$

Una segunda diferencia radica en el punto de partida que emplean ambos pensadores para fundamentar la metafísica: Lonergan coloca el principio de la reflexión filosófica en el deseo puro de conocer, mientras que Coreth toma la pregunta como principio y fundamento. A este respecto hay que decir que el punto de partida de Lonergan es más trascendental y menos empírico, en cuanto que el deseo de conocer sale a la luz explícitamente solo al final de la introspección trascendental. El punto de partida de Coreth, en cambio, es más empírico y menos trascendental, puesto que a él le interesa un punto de partida que todo hombre pueda constatar en su propia experiencia. Curiosamente, Francisco Galán comenta que el interés de Lonergan respecto del punto de partida es pedagógico: "Para Lonergan ningún punto de partida por radical que sea puede suplir la necesaria preparación pedagógica que ofrece Insight, la razón la conocemos bien: es el polimorfismo de la consciencia humana". ${ }^{89} \mathrm{Me}$ parece que la pregunta es más pedagógica que el deseo puro de conocer.

Respecto al resultado de la aplicación del método trascendental al punto de partida, la tercera y radical diferencia entre ellos es descrita por Coreth mismo; esta consiste en la comprensión del ser y en la función que desempeña dentro del método trascendental. Según Coreth, para Lonergan el ser es fundamentalmente lo mediato, mientras que para él es la "inmediación mediada o que se media a sí mismo". ${ }^{90}$

${ }^{87}$ E. Coreth, "Immediacy and Mediation of Being...", p. 35.

${ }^{88}$ Cfr. Ibid., p. 36.

${ }^{89}$ Francisco Galán, Metafísica como meta-metodología: Estudio de la propuesta de Bernard Lonergan, tesis doctoral, Universidad Iberoamericana, 2003, p. 177.

${ }^{90} \mathrm{Cfr}$. E. Coreth, "Immediacy and Mediation of Being...", pp. 33-4. 
"Para Lonergan el ser es solamente lo final, no es también lo primero; es solamente la meta de la mediación, no es también su inicio, y de aquí que no es también aquello que -en dinámica identidad-se media a sí mismo y continúa a definirse a sí mismo". ${ }^{91}$

Lo anterior se desprende del hecho que Lonergan considere el ser como aquello que puede ser conocido mediante juicios verdaderos. Más aún, el mismo sujeto es entendido por Lonergan en términos de objetividad, la cual no es otra cosa que el conocimiento del ser; por eso el sujeto puede ser considerado el "objeto" del cual es cierto asegurar que se afirma a sí mismo como cognoscente.

En cambio, Coreth concibe el ser como una relación dialéctica de mutuo condicionamiento entre sujeto y objeto, entre realización y concepto, de tal manera que el hombre solo puede preguntar por el ser porque siempre está junto al ser, y cuando el hombre pregunta es el ser mismo el que se hace cuestionable para hacerse autoluminoso a sí mismo. Pero el hombre jamás agota el ser, porque el concepto no logra captar lo ilimitado de la realización, y aun la misma realización no agota el horizonte absoluto del ser, pues de otra manera el hombre ya no preguntaría y sería todas las cosas. ${ }^{92}$

A este respecto, G. Sala comenta que la intención de Coreth de mediar trascendentalmente lo inmediato es oscura y confusa, puesto que, para Sala, el método trascendental "no media una intuición inmediata del ser, sino que pone de relieve que tal intuición no existe en absoluto". 93

Además, Sala defiende que la concepción lonerganiana del ser no es únicamente lo mediado, como afirma Coreth. ${ }^{94}$ Para demostrar lo

${ }^{91}$ Ibid., p. 46. Francisco Galán hace esta oportuna observación: “Quien enfatiza el carácter 'mediato' [Lonergan] destaca más la conceptualización, el lenguaje, el sentido, los horizontes culturales, históricos, etc., mientras que el partidario de la inmediatez [Coreth] apela sobre todo a la experiencia”. Francisco Galán, Metafísica como meta-metodología: Estudio de la propuesta de Bernard Lonergan, tesis doctoral, Universidad Iberoamericana, 2003, pp. 185-6. Los nombres entre corchetes son míos.

${ }^{92}$ Cfr. E. Coreth, "Immediacy and Mediation of Being...", pp. 41-2.

${ }^{93}$ Giovanni Sala, "Immediatezza e mediazione della conoscenza dell'essere. Riflessioni sull'epistemologia di E. Coreth e B. Lonergan”, Gregorianum 53, 1972, p. 72.

${ }^{94}$ Aquí se apunta un fascinante tema que rebasa los límites del presente artículo, pero que se propone como materia de una investigación ulterior: la presencia de Hegel en el pensamiento de Coreth y Lonergan. Por parte de Coreth, la influencia es directa, ya que se doctoró en 
anterior, señala que en el conocimiento se distingue esencialmente la noción del ser y el conocimiento verdadero del mismo que se tiene en el juicio; de aquí se sigue que todos nuestros conceptos son elaborados a posteriori, pero el concepto de ser no es elaborado de esta manera, sino que solo se tiene una noción de ser, es decir, una anticipación del objeto ilimitado de la orientación dinámica del espíritu. Esta noción de ser es operativa desde siempre en el ser humano; por esta razón no es una noción mediada, sino inmediata: es el a priori en sentido absoluto. ${ }^{95}$ Ahora bien, según Sala, cuando se dice que este inmediato se media, lo que se quiere decir es que se actualiza en el conocimiento verdadero de la estructura tríadica, pero un conocimiento directo e inmediato y un conocimiento estructurado no se excluyen. ${ }^{96}$

Considero que las objeciones de Sala son muy débiles; parece olvidar que todo conocimiento es mediado por la realización del sujeto; incluso, el conocimiento que tenemos del ser como noción nunca llegaría a nosotros si no es por mediación del pensar metafísico: "cada conocimiento de un objeto presupone el sujeto que conoce, que en su propia realización se media a sí mismo el contenido del conocimiento y hace de aquel contenido su objeto". 97

Por esta razón, Coreth propone como tarea necesaria la mediación trascendental de lo inmediato; éste es un conocimiento implícito, atemático, que hay que hacer temático y colocarlo en conceptos. Además, Sala no alcanza a distinguir que la noción de ser como deseo puro y anticipación pura se distingue del presaber del ser que propone Coreth: Lonergan llegará a actualizar el deseo de conocer hasta que se realice un juicio verdadero, mientras que Coreth ya tiene cierto conocimiento concreto del ser en cuanto que lo descubre como el horizonte absoluto de toda realización.

filosofía en la Universidad Gregoriana de Roma con una tesis sobre el ser dialéctico en la lógica de Hegel. Pero que la influencia de Hegel en Lonergan no fue menor, lo muestra el artículo de Mark D. Morelli "La lectura lonerganiana de Hegel", Revista de Filosofia UIA 135, 2013, pp. 199-225. El autor propone a Lonergan como el "Hegel católico". Ibid., p. 225.

${ }^{95}$ Cfr. Giovanni Sala, "Immediatezza e mediazione della conoscenza dell'essere. Riflessioni sull'epistemologia di E. Coreth e B. Lonergan”, pp. 74-6.

${ }^{96}$ Loc. cit.

${ }^{97}$ E. Coreth, "Immediacy and Mediation of Being...", pp. 34-5. 


\section{Conclusión}

La relevancia del tomismo trascendental, ilustrado en las propuestas de Lonergan y Coreth, radica en el hecho de afirmar que la metafísica es una posibilidad real de todo ser humano, sea o no filósofo, tenga o no un cierto cultivo del intelecto ${ }^{98}$ (metafísica latente en Lonergan, inmediata o implícita en Coreth). En esto, ambos pensadores se han mantenido fieles a la tradición tomista. Y para que esta metafísica latente e inmediata pueda llegar a ser una explicita y mediada, es decir, intelectualmente formulada, ambos recurrieron a Kant y su método trascendental, para dar cuenta de las condiciones de posibilidad de la realización cognoscitiva misma (el deseo puro de conocer de Lonergan y la pregunta por la pregunta en Coreth). Ambos puntos de partida llegan al ser como condición última de posibilidad del dinamismo cognoscitivo humano. Así, la metafísica se revela como una actividad ineludible del ser humano, no solo, como afirmaba Kant, como disposición natural, sino también como ciencia (ciencia fundamental y general según Coreth, ciencia que penetra, transforma y unifica todos los saberes según Lonergan). Que está fundamentación última de la metafísica cayó un tanto

${ }^{98}$ Compartimos las conclusiones de Francisco Galán respecto de Lonergan: “Lonergan propone la tarea metafísica como una conversación, del hombre de la calle con el científico, del religioso con el historiador, de las distintas culturas, de las diversas filosofías. En la conversación que integra escuchamos la voz del ser, pero no solo en los poetas, ni solo en griego, latín o alemán, también en la física cuántica y en la sabiduría maya y en la voz del niño de la calle. Necesitamos hacer metafísica, no para imponer una sola voz y declarar falsas a las demás, justo para dar peso a las distintas narraciones, para apreciar la dignidad de la voz del sin voz, hay que recordar que existe la verdad, que todos estamos hablando del misterio, que el misterio no es algo absurdo sino suprema inteligibilidad”. Francisco Galán, “¿Qué es hacer metafísica según el insight de Lonergan?”, p. 771. Por parte de Coreth, también compartimos las conclusiones de Hildegard Anegg: “¿La metafísica trascendental es una metafísica para la vida? ¿Puede proporcionarnos ideas que sean útiles para orientarnos en nuestros pensamientos sobre el mundo y la realidad en su totalidad? Con las consideraciones realizadas, quiero responder la pregunta con un sí. La metafísica trascendental contribuye a la clarificación y a la comprensión del ámbito del ser humano por su pensamiento metódico-existencial; a la comprensión de nuestro hablar sobre la realidad en general, por su pensamiento metódico-total; pero se hará claro la relación mutua de ambos ámbitos por la función integrativa de la aclaración metafísica". Hildegard Anegg, "Gelebte Metaphysik"-Metaphysik fur das Leben. Ein Beitrag zum Verständnis Transzendental Metaphysischen Denkens und Argumentierens, 2014, Innsbruck, tesis doctoral, p. 176. 
en el olvido debido al pensamiento débil posmoderno, así como al auge de la filosofía del lenguaje, es extensamente sabido. Pero Andrew Beards ha puesto de manifiesto que muchos nuevos miembros de la filosofía analítica han dirigido nuevamente su interés a las cuestiones metafísicas, ${ }^{99}$ de modo que puede afirmarse que el intento de Lonergan y Coreth sigue siendo un interlocutor válido en nuestros tiempos. Por todo lo anterior, Lonergan y Coreth pueden suscribir sin limitaciones la maravillosa sentencia de Kant: "Por esto, la metafísica ha existido siempre y existirá allí donde esté el hombre". ${ }^{100}$

99 "Me gustaría hacer notar que [...] el creciente interés en la metafísica entre los filósofos analíticos parece ir de la mano con una constante disminución de la hostilidad de su parte hacia la idea de los actos mentales y la investigación filosófica sobre ellos. [...] Y la lista de filósofos analíticos significativos que ya han abandonado la estricta observación wittgensteiniana de evitar el discurso sobre los actos mentales es impresionante. Incluye a Dummett, Searle, Chisholm, Shoemaker, Hintikka, David Mellor, J.R. Lucas y J.L. Mackie por mencionar solo unos pocos." Andrew Beards, Method in Metaphysics: Lonergan and the Future of Analytical Philosophy, 2008, Toronto, University of Toronto Press, p. 21.

${ }^{100}$ Immanuel Kant, Crítica de la razón pura, B 21. 
CITAM Derechos Reservados.

La reproducción total o parcial de este artículo se podrá hacer si el ITAM otorga la autorización previamente por escrito. 